\title{
Juegos marciales en las ciudades italianas antes del Renacimiento: entre fiesta $\mathrm{y}$ «deporte»*
}

\author{
Martial Games in Italian Cities before the Renaissance: Between \\ Pageant and «Sport»
}

\author{
Pablo Martín Prieto**
}

\section{RESUMEN ABSTRACT}

En el presente artículo se pasa revista a algunos de los ejemplos más característicos y significativos de juegos competitivos de actividad física que se celebraban en las ciudades del centro $y$ norte de Italia en tiempos medievales. Se contempla si tales juegos pueden ser considerados como «deportes» en el sentido más general y habitual del término (en su acepción contemporánea), así como se examina su relación con las festividades tradicionales y prácticas de entrenamiento militar ciudadano en el contexto de la vida urbana de la Italia de aquel tiempo. Una breve descripción de algunos de dichos juegos marciales ilustra su importancia social y cultural dentro de este contexto.

\section{PALABRAS CLAVE}

Fiesta, juego, deporte, milicia, ciudad, Italia.
This study examines some of the most characteristic and significant examples of competitive physical games that took place in the cities of the centre and the north of Italy in the Middle Ages.

The article assesses if these games can be considered sport in the general sense of the term (according to modern usage), as well as consider its relationship with traditional festivities and military training activities in the context of urban life in the Italy of that time. A brief description of certain martial games will demonstrate its social and cultural importance in this context.

KEY WORDS

Pageant, Games, Sport, Militias, Town, Italy.

\section{INTRODUCCIÓN}

Hace tiempo que se viene desarrollando esa gran área temática conocida como la «Historia de la vida cotidiana», vasto dominio en que quedan comprendidas líneas

* Fecha de recepción del artículo: 2013-10-1. Fecha de aceptación del artículo: 2014-01-18.

** Departamento de Historia Medieval de la Universidad Complutense de Madrid. C.e.: pablomartinprieto@ghis.ucm.es 
de investigación que se benefician en parte de las aportaciones de distintas disciplinas relacionadas, desde la Arqueología (el estudio del hábitat, el urbanismo, la casa y otras realidades de cultura material en torno a la vida cotidiana) hasta la Sociología (o la Antropología, con el estudio de las edades y actividades cotidianas de los hombres, y las concepciones en su torno), dando por resultado una gran variedad de enfoques y objetos (la alimentación, la salud y la enfermedad, la indumentaria, entre otros) ${ }^{1}$.

Dentro de esta amplia temática, la fiesta y el juego constituyen dos centros de interés interrelacionados, con su propio relieve y con una importante bibliografía. La fiesta ha sido estudiada desde una perspectiva histórica y también antropológica como un tiempo especial y diferenciado dentro de los ritmos de la vida cotidiana; un espacio de sociabilidad con caracteres propios; una ocasión de crear, afirmar y consolidar lazos de relación y cohesión social; un escape a la rutina; un ámbito para el recreo, la diversión y la creatividad. En la Edad Media, una serie de celebraciones más o menos tradicionales e institucionalizadas reunían al pueblo y a sus autoridades en un verdadero calendario festivo que puntuaba y amenizaba el discurrir del año².

Relacionado con el tema de la fiesta tenemos el del juego; tratando de juegos, los hay de muchos tipos, desde los juegos infantiles, que cumplen una función educativa en el desarrollo físico y mental de los niños, hasta los juegos de azar (tablas, dados, naipes), objeto preferido de censura por parte de los predicadores, pasando por los que aquí propiamente nos interesan: los juegos competitivos de actividad física. Podríamos llamarlos «deportes», más sencillamente. Pero entre los especialistas que se ocupan del tema no hay acuerdo. El concepto de «deporte», tal como lo empleamos hoy corrientemente, transmite unas connotaciones específicas que, de acuerdo con muchos autores, sólo se pueden aplicar al «deporte-espectáculo» o «deporte de masas» tal como se practica en la cultura occidental más o menos desde la época de la Revolución Industrial. Según este criterio restrictivo, las actividades lúdico-deportivas de épocas anteriores no son propiamente «deportes» en el sentido que hoy damos al término, sino más bien «juegos tradicionales» o, en todo caso, «deportes tradicionales», pero siempre mostrando una gran prevención frente al uso de la palabra «deporte» ${ }^{3}$. Para que se pueda hablar de «deporte», alegan, deberían darse ciertos elementos definitorios: la lógica del espectáculo; la institucionalización; una reglamentación precisa; una trascendencia cierta de orden económico, social, cultural y aun

1 Como aproximación preliminar a la amplitud de esta temática, valga la selección bibliográfica: RODRÍGUEZ LATORRE, L. E. - SÁNCHEZ PRECIADO, P. - SIGÜENZA PELARDA, C., «Vida cotidiana en la Edad Media: bibliografía», en IGLESIA DUARTE, J. I. de la (coord.), La vida cotidiana en la Edad Media. VIII Semana de Estudios Medievales (Nájera 1997), Logroño, 1998, pp. 407-483.

2 Una excelente introducción al fenómeno festivo en tiempos medievales: LADERO QUESADA, M. Á., Las fiestas en la cultura medieval, Barcelona, 2004.

${ }^{3}$ LE GOFF, J. - TRUONG, N., Une histoire du corps au Moyen Âge, París, 2003, rechazan expresamente la conveniencia de aplicar el concepto de «deporte» a los tiempos medievales. 
político; la conciencia de identificación o patriótica; conllevar elementos de carácter religioso, etc ${ }^{4}$. Pero precisamente, revisando esta misma lista, otros autores reconocen que los juegos tradicionales de época medieval cumplen en muchos casos con la mayor parte de dichos criterios, y en consecuencia merecerían ser considerados como verdaderos deportes, en el sentido corriente del término, sin mayor reserva ${ }^{5}$. Si bien diremos algo más sobre el tema, lo cierto es que no es este el lugar de entrar en la polémica. Podemos llamarlos «juegos» para no llamarlos "deportes", pero precisamente en el caso que nos ocupa, en las ciudades de la Italia prerrenacentista, estos juegos competitivos de actividad física revestían muchas de las características distintivas de verdaderos deportes, reglados, instituidos, con trascendencia económica, social, cultural, festiva, conmemorativa, con implicaciones políticas y religiosas.

En su famoso Libro de juegos o Libro del axedrez, dados e tablas, el rey de Castilla Alfonso X el Sabio recogió una distinción básica entre dos grandes categorías de juegos: los juegos de mesa, indicados para las mujeres, los viejos, los enfermos, los que cumplen pena de prisión, realizan un viaje por mar, o para aquellos que por cualquier otra circunstancia no pueden o no quieren salir de casa; y los juegos de movimiento, los juegos físicos o deportivos, de los que enumera: «esgrimir, luchar, correr, saltar, echar piedra o dardo, ferir la pellota, e otros iuegos de muchas naturas en que usan los omnes los miembros por que sean por ello mas rezios e reciban alegria» ${ }^{6}$. Centrándonos en estos últimos, los que llamaremos juegos competitivos de actividad física, todos se reducen a unos pocos tipos básicos: juegos de pelota, individuales o colectivos; carreras, a pie y a caballo; juegos de tiro o puntería, arrojando proyectiles como piedras, flechas, con arco o con ballesta; y lucha. Salta a la vista que el origen del deporte es la guerra o, más exactamente, la preparación para la misma, el entrenamiento militar. Históricamente, las primeras habilidades del deportista y las primeras disciplinas deportivas eran precisamente ejercicios útiles para la guerra: correr y saltar, cabalgar, luchar, lanzar proyectiles (ya fueran discos o jabalinas, etc.) ${ }^{7}$.

\footnotetext{
${ }^{4}$ Un resumen de tales argumentos: CAILLOIS, R. (dir.), Jeux et sports, París, 1967, pp. 1196-1197.

5 Tal es el criterio de la destacada especialista en la materia RODRIGO-ESTEBAN, M. L.: «Deporte, juego y espectáculo en la España medieval», en CANTARERO, L. - ÁVILA, R. (eds.), Ensayos sobre deportes. Perspectivas sociales e históricas, Guadalajara 2006, pp. 33-88; «Sobre prácticas deportivas en la España medieval: Aragón, siglos XIII-XV», en VAL VALDIVIESO, M. I. - MARTíNEZ SOPENA, P. (eds.), Homenaje a Julio Valdeón, Valladolid, 2009, t. III, pp. 503-520. Importantes estudios sobre el tema no evitan la denominación de "deportes» para estos juegos medievales: CARTER, J. M., Sports and Pastimes of the Middle Ages, Boston, 1988; MERDRIGNAC, B., Le sport au Moyen Âge, Rennes, 2002.

${ }^{6}$ ALFONSO X, Libro de juegos o libro del axedrez, dados e tablas, Biblioteca del Real Monasterio de San Lorenzo de El Escorial, ms. T. II. 6, fol. 1r. Por cierto, que en el mismo corpus alfonsí se vedan estos juegos a los clérigos: no sólo la práctica de los mismos, sino aun el ser de ellos espectadores: Partida I, título 5, ley 57. En cambio, forman parte del solaz y de la formación del rey y sus hijos: Partida II, título 5, ley 21, y título 7, ley 10 .

7 SANSONE, D., Greek Athletes and the Genesis of Sport, Berkeley-Los Ángeles, 1988.
} 
Pero en este estudio hemos elegido dejar de lado, como un caso aparte con sus caracteres propios, las justas y torneos caballerescos ${ }^{8}$, para centrarnos en los juegos villanos, en los que no sólo participaban profesionales de la milicia, no sólo nobles, sino potencialmente toda la población. El escenario escogido es Italia; allí, ciertos de estos juegos revistieron particular vistosidad y su tradición - $\mathrm{o}$ al menos su memoria - perduró largo tiempo, habiendo revivido incluso en nuestros días. La Italia del norte y centro en la Plena Edad Media es la Italia de las pequeñas comunidades o ciudades-Estado, siempre en continua rivalidad ${ }^{9}$. El intermitente estado de guerra, la lucha frecuente entre estas ciudades aumentaba a ojos de sus habitantes la importancia del entrenamiento militar que, informalmente -y para los niños educativamente hablando- se concreta en juegos «marciales», que llamaremos así porque venían a emular en cierto modo el espíritu de aquellos juegos de Marte de la Antigüedad, y también por su carácter propedéutico (es decir, preparatorio) para la milicia, para la guerra.

\section{1. ¿HUBO «DEPORTES»EN LA EDAD MEDIA? MARCO CONCEPTUAL Y SOCIOLÓGICO}

Como necesaria contextualización del análisis del caso escogido, no estará de más trazar en este punto un cuadro más preciso sobre el alcance de la posible y propuesta consideración como deportes de ciertos juegos competitivos medievales, y las funciones que cumplían en el seno de las sociedades que les dieron origen.

En un estudio que con el tiempo acabaría convirtiéndose en una referencia clásica sobre el tema, el influyente historiador norteamericano Charles Homer Haskins (conocido sobre todo por haber acuñado y difundido la noción de «Renacimiento del siglo XIl») no dudó en hablar de deportes medievales ${ }^{10}$. Al hacerlo, se insertaba en una corriente historiográfica que desde las décadas finales del siglo XIX —coincidiendo en parte con la revalorización social de este tipo de actividades al hilo del primer desarrollo de los deportes contemporáneos tal como hoy los conocemos-, se interesaba por los precedentes históricos de dichos deportes ${ }^{11}$. El enfoque de

${ }^{8}$ Fascinante objeto de estudio que cuenta con una copiosa bibliografía, de la que sólo citaremos, a título de ejemplo, dos conocidos títulos: FLECKENSTEIN, J. (ed.), Das ritterliche Turnier im Mittelalter: Beiträge zu einer vergleichenden Formen und Verhaltensgeschichte des Rittertums, Gotinga, 1985; BARBER, R. - BARKER, J., Tournaments. Jousts. Chivalry and Pageants in the Middle Ages, Woodbridge, 1989.

${ }^{9}$ La bibliografía sobre el tema es inmensa, en continua renovación; casi al azar, citaremos WALEY, D., Las ciudades-república italianas, Madrid, 1969.

10 HASKINS, C. H., «The Latin Literature of Sport», Speculum, 2 (1927), pp. 235-252.

11 Algunos ejemplos dentro de esta misma línea historiográfica, que incluso se remonta a los pioneros o precursores del estudio ‘etnográfico' del deporte: HALKEN, H., The National Sports of Great Britain, Londres, 1821; JUSSERAND, J. J., Les sports et jeux d'exercise dans l'ancienne France, París, 1901; HACKWOOD, F., Old English Sports, Londres, 1907; MADDEN, D. H., A Chapter of Medieval History: The Fathers of the Literature of Field Sports and Horses, Londres, 1924; MAGOUN, F. P., History 
estos historiadores clásicos, habitualmente adscritos al paradigma positivista -y en todo caso anteriores a la renovación de métodos ligados a los ámbitos antropológico y sociológico-, no encontraba dificultad alguna en conferir el marbete de deportes a aquellos juegos competitivos de actividad física medievales que analizaban. Por analogía, en el fondo, pero sin ahondar en una categorización conceptual especial, parecía natural, pues, tratar de deportes medievales. Por su parte, en su famoso libro Homo ludens, Johan Huizinga planteó una tesis fecunda de cara a los posteriores estudios sobre el tema: a saber, que el juego es una constante en la evolución humana en cualquier tiempo y lugar, y una de las fuerzas creadoras de la cultura (en lo que existe razonable consenso), pero también (y aquí se bifurcan los caminos entre quienes se adhieren a la idea de Huizinga y quienes la refutan), que en todas las culturas y épocas los juegos -y por ende los deportes, por cuanto tienen de juego- responden a una actitud psicológica invariable, el «espíritu de competición» de acuerdo a unas reglas ${ }^{12}$.

Desde puntos de vista afectos a marcos conceptuales del trabajo historiográfico relacionados con la antropología y la sociología, otros autores niegan este último supuesto: según ellos, el peligro de la extrapolación y el anacronismo acecha tras cualquier intento de identificar mecánica o simplemente algún deporte de nuestro tiempo con sus pretendidos precedentes de época medieval, e incluso se incurre en censurable defecto de rigor al pretender aplicar categorías y marcos mentales y sociales del presente a la descripción de fenómenos del pasado que, en sentido estricto, no son comparables, o cuando menos, que efectivamente lo sean, ha de ser investigado y justificado previamente a cualquier equiparación ${ }^{13}$. De acuerdo con este paradigma interpretativo estricto, no cabe tanto indagar si aquellas prácticas medievales son precedentes de los actuales deportes, sino que es oportuno plantearse si realmente se trata, en aquel caso, de deportes. Como hemos visto en nuestra introducción, este criterio restrictivo tiende a reservar la denominación de deportes para los de la época industrial, contemporánea de nuestra civilización occidental; éstos habrían surgido, pues, de la ruptura de marcos sociales y mentales del ancien régime, y de su concepción como autónomos y desligados de otras actividades (ritos, fiestas) de las que con anterioridad eran inseparables ${ }^{14}$.

El término deporte procede, a través del inglés moderno, del francés medieval desport (documentado por primera vez hacia 1160, en el Roman d'Eneas), a su vez del latín deportare. En una y otra lenguas, el campo semántico asociado remite a la noción de desviación: en latín deportare es desterrar, separar o desviar; en francés medieval, se desporter (se deporter) significa asimismo desviarse o separarse, a lo que se unirá un sentido especial: desviarse o separarse de las ocupa-

of Football: From the Beginnings to 1871, Bochum, 1938; HOLE, C., English Sports and Pastimes, Londres, 1949.

12 HUIZINGA, J., Homo ludens, proeve eener bepaling van het spel-element der cultuur, Leiden, 1938.

${ }_{13}$ ELIAS, N. - DUNNING, E., Sport et civilisation. La violence maîtrisée, París, 1998, pp. 13-14.

${ }^{14}$ BOURDIEU, P., "Comment peut-on être sportif?», en Questions de sociologie, París, 1980, p. 175. 
ciones cotidianas, recrearse, entretenerse (esto es, distraerse, divertirse, con la doble acepción de estos términos, situados a caballo entre la noción de recreo y la de desviación o extravío). Genérica y originariamente, el campo semántico del deporte se asocia al ocio o recreo ${ }^{15}$, y por extensión, a la fiesta y al juego.

Esta nota etimológica plantea una nueva cuestión: la de la relación entre trabajo y ocio en la Edad Media, y el lugar del deporte, o de las actividades medievales que se le parecen, dentro de este esquema ${ }^{16}$. El juego, y por ende también los juegos competitivos de actividad física, florecen en el tiempo y el espacio de la fiesta; cuando se practican, imponen un paréntesis al trabajo en el ritmo de la vida cotidiana; de ahí que el juego pueda definirse como el negativo o envés del trabajo, pero también como algo contrapuesto a «lo real» (en el sentido en que las cosas se hacen o «en serio» o «en juego») ${ }^{17}$. Pero ni todo juego es deporte, ni toda actividad de ejercicio físico lo es tampoco: para serlo, el deporte ha de involucrar un aspecto de competición y un marco de organización o regulación ${ }^{18}$. Pero precisamente, si aceptamos la centralidad de estas dos dimensiones como definitoria del fenómeno deportivo, entonces habrá que convenir que los juegos competitivos de actividad física de la Edad Media eran deportes, propiamente hablando, o siquiera por analogía con los actuales ${ }^{19}$.

\section{IL PALIO O CARRERA DE CABALLOS}

Dejando a un lado el problema de definir con precisión, tomando en cuenta las aportaciones enfrentadas de diversos estudiosos, la naturaleza de este tipo de juegos competitivos o deportes, pasamos a describir algunos de los que se practicaban en las ciudades del norte y centro de Italia, tal como se puede documentar al menos desde el siglo XIII. Uno de los más vistosos, apreciados y frecuentes era il gioco del palio, esto es, cierto tipo de carreras de caballos que al menos desde el siglo XIII se celebraban con todo aparato y el respaldo de las autoridades públicas comunales en muchas ciudades del norte y centro de Italia ${ }^{20}$. El nombre del

15 TRAPERO, M., El campo semántico ‘deporte', Santa Cruz de Tenerife, 1979.

${ }^{16}$ Cuando Jean VERDON publicó su estudio Les loisirs en France au Moyen Âge, París, 1980, reconoció abiertamente el anacronismo implícito en el título (por otra parte, difícilmente evitable).

17 GUSDOFF, G., «L'esprit des jeux», en CAILLOIS, R. (dir.), Jeux et sports (Encyclopédie de la Pléïade, vol. 23), París, 1967, p. 1179: «Le jeu n'est le jeu que par référence à un certain sens du réel. Si le jeu devient le sens du réel, il n'y a plus jeu, ni réel».

18 Precisamente, contiene esos dos aspectos la definición de deporte que da Norbert Elias en la obra citada, ELIAS - DUNNING, Sport et civilisation, p. 214: «activité de groupe organisée qui repose sur une compétition entre au moins deux partis. II nécessite un éffort physique et obéit à des regles dont certaines limitent, lorsque le besoin s'en fait sentir, l'usage de la force physique».

19 O, según la fórmula de BOUET, M. (Signification du sport, París, 1968), citada por DURING, B., Des jeux aux sports. Repères et documents en histoire des activités physiques, París, 1990, p. 42, la Edad Media «contenait toute la matière de ce qui deviendra peu à peu le sport, mais que la forme resta frustre».

20 Sigue siendo una lectura de referencia básica el trabajo pionero de HEYWOOD, W., Palio and Ponte. An Account of the Sports of Central Italy from the Age of Dante to the $20^{\text {th }}$ Century, Londres, 1904: sobre los palios, que tratamos en esta sección, véanse especialmente las pp. 6-92. 
juego provenía de su premio o recompensa: el palio, del latín pallium, era en origen una capa de forma rectangular que, cuando se llevaba exhibiéndola en alto hacía las veces de una enseña, bandera o estandarte. En este juego, un palio, esto es, un buen paño, un paño de precio, era el trofeo para el vencedor de una carrera de caballos, de donde las expresiones "correre per vincere il palio" o más sencillamente, "correre il palio", que dan nombre al juego. Se trataba de una verdadera celebración ciudadana, que congregaba a todos, grandes y pequeños, en el marco de una gran fiesta, con carácter conmemorativo, y contando con el apoyo de la autoridad pública. Dante hace referencia en su Commedia (Paradiso, canto 16) al famoso palio de San Juan Bautista, carrera ecuestre que cada año se celebraba en Florencia en la fecha del santo, cruzando toda la ciudad, del barrio de San Pancrazio (al oeste) hasta el barrio de San Piero (al este), atravesando el Mercato Vecchio, la plaza central ${ }^{21}$. Otros muchos palios semejantes se celebraban en otras ciudades, de las que se podrían citar Verona, Pisa, Ferrara, Padua, Bolonia, entre otras; pero por hablar de uno solo tenemos que escoger el de Siena.

En 1260, con ocasión de una guerra contra Florencia, las autoridades y el pueblo de Siena realizaron un voto especial y solemne por el que su ciudad entraba en vasallaje de la mismísima Virgen María, a cuya protección se confiaron para hacer frente al intento de invasión florentino. Reforzados por esta nueva alianza con una tan alta señora, los sieneses se aprestaron a la lucha, salieron al encuentro de los invasores florentinos y, contra todo pronóstico, los derrotaron en la batalla de Rosaio, en la que incluso lograron capturar al enemigo una carreta -il carroccio- con las enseñas de Florencia (las enseñas son los palios, recuérdese). En conmemoración oficial de este voto y de esta victoria, Siena celebró desde entonces un gran palio o carrera ecuestre por la Asunción, el 15 de agosto. Esa es la tradición, si bien parece que ya antes se venían celebrando carreras ecuestres, pero fuera de la ciudad, usando sus puertas como metas de llegada. Aunque con el tiempo se llegaron a celebrar varias de estas carreras perfectamente institucionalizadas dentro del calendario festivo local, la más solemne y principal de todas era este palio que cada año se celebraba con ocasión de la referida fiesta en honor de la Virgen, señora de la ciudad. Esta fiesta mayor de la ciudad contaba con la participación y desfile solemne de las autoridades comunales y magistrados, miembros de los gremios y oficios, y sobre todo, consistía en la celebración de este palio, ocasión patriótico-conmemorativa en recuerdo de aquella sonada victoria militar sobre los florentinos. En el marco de la festividad patriótica, el palio, con sus innegables resonancias e implicaciones militares, se erigía así en uno de los centros principales de las celebraciones ciudadanas, adquiriendo dentro de

${ }^{21}$ La extremada popularidad de esta celebración en la Florencia de los tiempos de Dante tenía incluso sobre aviso a los predicadores, celosos de que un entretenimiento cívico-deportivo pudiera detraer de lo divino la atención del pueblo, a quien Giordano de Pisa pide que «'l cuore sia all'orazione, e non [...] al cavallo»: PISA, G. da, Prediche recitate in Firenze dal MCCCIII al MCCCIX, Milán, 1839, t. II, p. 244. 
éstas, para los habitantes de la ciudad y para sus autoridades, una significación especial.

En el siglo XIV consta que había ya en Siena calles y plazas pavimentadas, con previsiones para su mantenimiento y limpieza a cargo del municipio. De esta época data el esquema tradicional del palio de Siena que, con algunas modificaciones posteriores, se conservará en esencia hasta nuestros días, como una carrera de caballos cerrada, dando varias vueltas a la gran plaza central de la ciudad, probablemente su antiguo foro, llamada Piazza del Campo, la cual consistía en casi un semicírculo pavimentado y con algunas irregularidades suaves de nivel. Precedidos por las fanfarrias de los heraldos que anunciaban el juego, varios equipos que se distinguían por el uso de colores y estandartes identificativos y representaban la rivalidad de otros tantos sectores o distritos de la ciudad, competían ritual y regladamente por el palio en esta famosa carrera de caballos. Pero decir «carrera de caballos» realmente es poco, no indica bien el vértigo y el riesgo emocionante de la prueba: teniendo en cuenta sus ángulos, resulta difícil imaginar un lugar más peligroso o menos conveniente para una carrera de caballos que esta plaza, cuyos cerrados giros esquineros hacen pensar más bien en los que había que dar sobre la espina del antiguo circo romano o del hipódromo de Constantinopla. A ello había que sumar, según descripciones de la carrera, que durante la misma los jinetes llevaban cascos y otras protecciones, no sólo como precaución frente a una caída fortuita, sino provocada: y es que formaba parte del juego que los jinetes lucharan por desmontar a sus rivales, o cortarles el paso, sin que en todo ello escatimaran los participantes en propinarse y recibir toda clase de golpes, acciones que desde la perspectiva de una carrera ecuestre actual, se considerarían, precisamente, antideportivas, cuando al parecer en la época formaban parte inseparable de la «salsa» del juego.

\section{LAS BATTAGLIE Y SUS DIVERSAS MODALIDADES}

Con todo, esta suerte de espectáculo podía considerarse entre los más limpios y menos cruentos de la época. Otro tipo de juego marcial habitual en las ciudades de Italia desde antes del Renacimiento eran las llamadas batallas, battaglie en italiano ${ }^{22}$. En origen, como el nombre indica, eran auténticas batallas armadas de entrenamiento con las que la población masculina en edad militar se preparaba para la guerra combatiendo en equipo contra equipos rivales formados por sus mismos conciudadanos ${ }^{23}$. Y en origen, si bien se aceptaba que estas batallas se libraban "per gioco e non per realtà" («por juego y no de verdad»), no es menos

22 HEYWOOD, Palio and Ponte, pp. 93-196. BALESTRACCI, D., La festa in armi, Roma-Bari, 2001. COMBA, R. - RAO, R. (coords.), Giochi e giocattoli nel Medioevo piemontese e ligure, Roca de' Baldi, 2005.

${ }^{23}$ El origen y el carácter de estos ejercicios de entrenamiento militar debe algo a los que en época romana se practicaban en los «campos de Marte» de muchas ciudades de Italia, y a los que prescribe Vegecio como preparación para el combate en su Epitoma rei militaris. 
cierto que a menudo resultaban tremendamente cruentas, pues se usaban en ellas armas de combate reales y regularmente se cobraban un inevitable tributo de sangre (con heridos y muertos). Al uso primigenio de verdaderas armas de combate alude el nombre que primero tuvieron estas batallas: el juego del mazzascudo, pues se jugaba con maza, un arma de mano contundente, y con escudo para defenderse de los golpes rivales. En Siena, el juego se llamaba del elmora, esto es, de los yelmos, por los yelmos o cascos que llevaban sus participantes armados para defenderse de las armas de los contrarios. En ocasiones, las batallas se dirimían a pedradas, como en las famosas batallas de piedras, las sassaiole (en latín, litomachiae), la más conocida la de Perugia ${ }^{24}$ (progresivas adaptaciones de estas batallas de piedras serán, en Italia y en otras partes, las invernales batallas de bolas de nieve ${ }^{25}$ y las batallas con frutas como elemento arrojadizo ${ }^{26}$ ).

Realmente, como las heridas y muertes causadas durante estos juegos de batalla se consideraban infligidas "per gioco e non per realtà", no daban lugar a enemistad ni responsabilidad penal ${ }^{27}$, y por ello las autoridades sólo actuaban, en sentido represivo, cuando el número de muertos rebasaba alguna vez el elástico concepto de lo que se considera «tolerable» ${ }^{28}$. Existen suficientes testimonios de esta relativa inhibición de las autoridades, que dejaban hacer al pueblo, es decir, le dejaban disfrutar de este popular y violento entretenimiento colectivo: sus efectos adversos, las heridas y lesiones, más bien se consideraban como algo «cómico», jovial y festivo; y las autoridades sólo prohibían estos juegos de batalla cuando degeneraban en altercados graves o enfrentamientos que pudieran amenazar el orden público o ser susceptibles de posibles lecturas o derivaciones políticas desestabilizadoras para el mismo statu quo del orden o del gobierno de la ciudad. Pues muchas veces, además de su función originaria educativa como entrenamiento militar de la población, estas batallas actuaban como auténticas válvulas de escape y expresión de odios larvados, enemistades profundas, venganzas familiares, pudiendo

${ }^{24}$ MAIRE VIGUER, J. C., «Un jeu bien mal tempéré. Le 'ludus battaglie' de Pérouse», en Histoire et société. Mélanges Georges Duby, Aix-en-Provence, 1992, t. II, pp. 195-208 [206]. Consta que en 1425 las autoridades de Perugia se dirigieron oficialmente a las de Siena, donde estaba a la sazón san Bernardino, pidiendo la intervención del santo para intentar abolir este peligroso juego tradicional: BULLETTI, E., «Nuovi documenti Bernardiniani», Bulletino di Studi Bernardiniani IX/2 (1943) 150-161 [151-152]. Sobre su figura y predicaciones: ORIGO, I., The World of San Bernardino, Nueva York, 1962 DELCORNO, C. (ed.), Bernardino da Siena. Prediche volgari sul campo di Siena 1427, Milán, 1989; POLECRITTI, C. L., Preaching Peace in Renaissance Italy. Bernardino of Siena and His Audience, Washington D. C., 2000.

${ }^{25}$ ALEXANDRE-BIDON, D., "Les jeux et sports d'hiver au Moyen Âge et la Renaissance», en Jeux, sports et divertissements au Moyen Âge et à l'Âge Classique. Actes du $116^{\mathrm{e}}$ Congrès National des Sociétés Savantes (Chambéry 1991). Section d'histoire médiévale et de philologie, París, 1993, pp. 143-156.

26 LADERO QUESADA, Las fiestas, p. 138.

27 «Sembra, infatti, che le uccisioni venissero generalmente considerate accidentali e perciò non dessero origine a vendette o inimicizie e quindi che vi fosse un numero di perdite umane considerato inevitabile»: RIZZI, A., Ludus / ludere. Giocare in Italia alla fine del medio evo, Treviso-Roma, 1995, p. 42.

28 SETTIA, A. A., «La 'battaglia': un gioco violento fra permisivita e interdizione», en Gioco e giustizia nell'Italia di Comune, Roma, 1993, pp. 121-132. 
incluso encubrir, bajo la violencia del juego, conflictos sociales o conatos de rebelión social o política frente al orden establecido o contra la facción gobernante en cada momento. Como válvula de escape y expresión de odios reprimidos, violencias latentes y tensiones acumuladas en el seno de la vida ciudadana, estas batallas podían incluso parecer convenientes y psicológicamente saludables; pero usarlas como medio para enmascarar rebeliones o desafíos contra el orden social establecido era algo que las autoridades no estaban dispuestas a tolerar ${ }^{29}$.

Lo cierto es que a partir de mediados del siglo XIII, se aprecia una tendencia a regular estas batallas prohibiendo las armas más letales: así, un estatuto de la comunidad de Vercelli en 1241 prohíbe las mazas de plomo o de bronce ${ }^{30}$, y otro de Parma en 1255 sólo permite usar espadas y mazas de madera ${ }^{31}$. Ya en la segunda mitad del siglo XIII comienzan las prohibiciones de estos juegos de batalla, sobre todo por motivos de orden público. Y algo más: por mediación de la Iglesia, y en esta segunda mitad del siglo XIII por influjo de la predicación de los frailes, de los mendicantes, la batalla evolucionará hacia formas menos cruentas, más «humanas»: del combate armado, del mazzascudo, al combate sin otras armas que los propios puños: el juego de los puños. A este respecto es interesante recordar, como precursor de esta tendencia que favorecía desde los púlpitos y las cátedras la reconversión de las batallas ciudadanas armadas en contiendas sin armas, la figura del obispo san Ubaldo de Gubbio, que vivió en la primera mitad del siglo XII, y guió a su ciudad a la victoria en una guerra contra once comunidades rivales coligadas (Spoleto, Perugia, Foligno, Asís y otras) ${ }^{32}$. Según la leyenda de este santo obispo ${ }^{33}$, con ocasión de una de estas multitudinarias batallas «deportivas» que tenía lugar en su ciudad, san Ubaldo se interpuso entre las espadas desenvainadas de los contendientes con su propio cuerpo, fingió caer herido a tierra y así consiguió detener la batalla; más tarde se le atribuirá haber sido el introductor de las batallas de puños como sustituto menos cruento de las batallas armadas, y como tal continúa siendo un santo popular cuya memoria habrá seguido vinculada, hasta los tiempos actuales, con este hecho fundamental de su vida y, por extensión, con el patrocinio del arte pugilístico ${ }^{34}$.

${ }^{29}$ RIZZI, A., «Violenzia e povertà per gioco alla fine del medio evo», en Ludus / ludere, pp. 39-52.

${ }^{30}$ ADRIANI, G. (ed.), Statuti del comune di Vercelli, Turín, 1877, p. 64.

${ }^{31}$ RONCHINI, A. (ed.), Monumenta historica ad provincias Parmensem et Placentinam pertinentia, Parma, 1856, t. I, p. 283.

${ }^{32}$ ROGARI, O., Vita di S. Ubaldo, Perugia, 1960; FANUCCI, A. M., Ubaldo Baldassini, novecento anni dopo, Gubbio, 1986. Fallecido en 1160, su fama de santidad llevó al papa Celestino III a canonizarlo en 1192; su cuerpo incorrupto se trasladó entonces de su primer sepulcro en la catedral a una basílica nueva especialmente consagrada para ello en el Monte Ingino, dominando la ciudad. Allí se conserva desde entonces y se expone a la veneración de los fieles en una urna de cristal. CENCl, P., I/ culto di S. Ubaldo dalla morte alla traslazione, Gubbio, 1994.

${ }_{33}$ La leyenda medieval de este santo (leyenda, legenda, es lo que hay que leer sobre su vida en la misa de la fiesta de un santo) se debe a Giordano da TIFERNO, Vita di S. Ubaldo (ed. FANUCCI, A. M.), Gubbio, 1992.

${ }^{34}$ Como ejemplo de esta tendencia, véase la consideración y la memoria de san Ubaldo como vinculada al pugilismo en el contexto de una mesa redonda sobre «ética y deporte» (celebrada en Gubbio, el 25 de febrero de 2005): http://www.archiviombx.com/start/modules.php?name=News\&file=article\&sid=1770 


\section{UN PARÉNTESIS: LA ACTITUD DE LA IGLESIA HACIA LOS JUEGOS $Y$ «DEPORTES»}

El ejemplo del obispo san Ubaldo de Gubbio, cuya carismática figura se presenta legendariamente ligada a la dulcificación y atenuación de las crueldades y asperezas de este tipo de batallas cívicas armadas, nos sugiere plantear, siquiera con la brevedad de un paréntesis, la cuestión sobre la actitud que las autoridades eclesiásticas y los intelectuales de la época mantuvieron en relación con la esfera de los juegos en general, y de los que - anacrónicamente o por analogía - hemos dado en llamar, para entendernos, «deportes medievales» 35 .

Las prohibiciones de torneos en la época del movimiento de la paz de Dios, así como las prevenciones contra las vanidades y seducciones mundanas propias de las corrientes ascéticas del pensamiento cristiano, desde los padres del desierto fundadores del monacato hasta san Bernardo de Claraval, definen uno de los polos entre los que oscila a lo largo de la Edad Media dicha actitud general hacia el cuerpo ${ }^{36}$, el juego, y -ambos ingredientes combinados- los juegos de actividad física, nuestros «deportes»: el polo de la censura y la desconfianza. Frente a él, el polo de la aceptación de tales actividades en razón de su utilidad social ${ }^{37}$, y la comprensión hacia lo que tienen de saludable o beneficioso, entroncando en parte con el venero de la Antigüedad clásica ${ }^{38}$. En la esfera del pensamiento esco-

[última consulta: 2013/09/19]. Sobre la historia del pugilismo entre el final de la Antigüedad y el nacimiento del boxeo actual según las reglas del marqués de Queensberry: ERNOEHAZY, W. S., «An ancient art, a long absence», Western Martial Arts Illustrated vol. 1, no. 1 (2007) 24-29; PFRENGER, K., "Boxing's ancestors", Western Martial Arts Illustrated vol. 1, no. 1 (2007) 48-53.

${ }_{35}$ Al respecto, véase MERDRIGNAC, Le sport au Moyen Âge, pp. 49-65 ; RIZZI, «L'intervento della Chiesa", en Ludus / ludere, pp. 103-147.

${ }^{36}$ LE GOFF - TRUONG, Une histoire du corps au Moyen Âge, op. cit.

${ }_{37}$ Como es bien sabido, la Iglesia privó primeramente de sagrada sepultura a quienes fallecieran combatiendo en torneos, aunque se hubieran reconciliado mediante penitencia: así, en los concilios regionales de Clermont 1130 (canon 9), Reims 1131 (canon 12), de donde la prohibición pasa a los ecuménicos concilios Lateranense II 1139 (canon 14) y Lateranense III 1179 (canon 20). Más tarde, sin embargo, la Iglesia fue tolerando los torneos en la medida en que apreciaba su utilidad como entrenamiento de los caballeros, especialmente de cara a las necesidades de las cruzadas, y esto culmina en la conocida decretal de Juan XXII en 1316 levantando aquella primera prohibición: von RIGGER, P. J., Instituciones de jurisprudencia eclesiástica, Madrid, 1841, t. 5, p. 139.

${ }_{38}$ El legado de la Antigüedad grecolatina, con lo que en dicho contexto cultural significaron los «deportes», comprensiblemente está presente de manera muy directa en san Isidoro de Sevilla, quien sin apartarse de la censura cristiana de los juegos gladiatorios del circo corriente desde Tertuliano, alaba en sus Etimologías los ejercicios gimnásticos o atléticos (Etymologiae, 18, 17: "Gymnicus ludus est velocitatis ac virium gloria»), y recomienda las ventajas del entrenamiento físico dentro de su programa educativo ideal para la clase dirigente (en sus Institutionum disciplinae). Sobre la aproximación isidoriana a los "deportes", véase VAL NAVAL, P., «El deporte en las Etimologías de Isidoro de Sevilla", CANTARERO, L. - MEDINA, X. - SÁNCHEZ, R. (coords.), Actualidad en el deporte. Investigación y aplicación, San Sebastián, 2008, pp. 247-264. También esa referencia anticuarista se percibe con claridad en autores del Ilamado «Renacimiento del siglo XII»: por ejemplo, cuando Hugo de San Víctor trata de la scientia theatralis (nótese que no es para él ars o técnica, sino scientia o conocimiento) como el conjunto de disciplinas del teatro (hoy diríamos, "del espectáculo»), incluyendo los juegos de actividad física (Hugues de Saint Victor. L'art de lire. Didascalion —ed. LEMOINE, M.-, París, 1991, p. 121; vid. LEMOINE, M., "Le sport chez Hugues de Saint Victor", en Jeux, sports et divertissements, 
lástico, desde el siglo XII existe una corriente proclive a reconocer, desde un punto de vista tanto fisiológico ${ }^{39}$ como psicológico ${ }^{40}$, los aspectos positivos del ejercicio físico para la persona y para la sociedad, al mismo tiempo que se procede a una revalorización del juego como actividad de ocio y recreación necesaria para el equilibrio individual y social ${ }^{41}$. En este contexto, puede apreciarse una evolución en el mismo seno de la «cultura oficial» de la época, dentro de la órbita erudita y eclesiástica. Desde el siglo XIII, la predicación de las órdenes mendicantes en la ciudad toca temas vivos y actuales de la sociedad de su tiempo, y así las recomendaciones de los frailes y otros predicadores, siguiendo la línea «pacifista» ejemplificada por san Ubaldo de Gubbio, contribuirán durante la Baja Edad Media a la mencionada transformación de prácticas festivas, lúdico-deportivas como estas battaglie, en el sentido de humanizarlas y hacerlas menos cruentas, especialmente mediante la supresión de las armas de combate o su substitución por alternativas menos contundentes, reduciendo así el riesgo físico al que se exponían los participantes ${ }^{42}$.

\section{LA EVOLUCIÓN DE LAS BATTAGLIE: EL PONTE DE PISA Y EL CALCIO DE FLORENCIA}

Tanto si, abundando en el ejemplo del obispo san Ubaldo, la tendencia a promover alternativas dulcificadas a las batallas armadas provino de instancias eclesiásticas, como si el impulso hacia dicha substitución surge de la propia lógica interna de tales confrontaciones en el ámbito cívico — por los reglamentos y estatutos comunales-, lo cierto es que a partir de la segunda mitad del siglo XIII, decaerán en muchas ciudades las batallas armadas tal y como hasta entonces se habían venido practicando, y serán reemplazadas, o bien por versiones atenuadas de las mismas, empleando armas de madera o de entrenamiento y no verdaderas armas de filo y de combate, o bien por los llamados «juegos de puños», donde no

pp. 136-140); o cuando en un sermón Julián de Vezelay describe un enfrentamiento pugilístico del circo, siguiendo en parte el modelo de la Eneida, pero aludiendo también a su propio tiempo — «nuestros púgiles actuales», dice al auditorio que escucha su sermón (Sermones —ed. VORREUX, D.-, París, 1972, t. II, p. 596).

39 Hugo de San Víctor indica que «con un ejercicio moderado se nutre el calor natural del cuerpo y se repone el ánimo con alegría» («temperato motu naturalis calor nutritur in corpore, et laetitia animus reparatur»: Hugonis de Sancto Victore Didascalion de studio legendi -ed. BUTTIMER, C. H.Washington, 1939, p. 44). Los sermonarios del siglo XV toleran los juegos practicados «causa virtutis corporis exercende» (BUSTI, B., Rosarium sermonum, Venecia, 1498, fol. 188r).

40 Santo Tomás de Aquino defiende los juegos como evasión o distracción y descanso del trabajo (Tratado de la fortaleza, cuestión 138, artículo 1, respuesta 3).

41 El Aquinate no sólo pondera la necesidad individual del juego para el descanso del alma, sino que también indica su utilidad para la convivencia social (Tratado de la templanza, cuestión 168, artículo 2, respuesta 2).

42 Un ejemplo del punto de vista teológico sobre la cuestión en el norte de Italia: CECCARELLI, G., «ll gioco nella riflessione dei teologi di area piamontesa: da Alessandro di Alessandria ad Angelo da Chivasso", en COMBA - RAO, Giochi e giocatelli, pp. 107-122. 
intervenían otras armas que éstos. Entrando a describir someramente los juegos derivados de esta tendencia, nos detendremos únicamente en dos de los más famosos y representativos.

En primer lugar, el famoso Gioco del Ponte o juego del puente, de Pisa ${ }^{43}$. Se trataba de una más de estas «batallas» tan en boga en casi todas las ciudades de la Toscana y la Umbría: en origen, un ejercicio militar para peones, para los miembros de la soldadesca de a pie que durante el año se organizaban y entrenaban en compañías o sociedades de armas, por parroquias, y el 17 de enero, día de san Antonio, en el marco de una gran festividad ciudadana, se agrupaban formando dos bandos que lucharían ritualmente - pero también con encono y verdadero esfuerzo- por tomar el control del famoso y estratégico puente llamado Ponte del Mezzo, sobre el Arno. Esta batalla o juego del puente enfrentaba, pues, a los pisanos que vivían al norte y al sur del Arno. Seis equipos o squadre formaban en cada bando: seis por el norte, seis por el sur; y cada squadra, integrada por entre treinta y treinta y seis soldati, tenía y exhibía con orgullo su propio estandarte y sus colores identificativos ${ }^{44}$. Cada año, el ritual del juego se ponía en marcha con un desafío que, con sones guerreros, correspondía hacer al bando que había perdido en la última confrontación, y recibir al vigente campeón. Varios días antes del 17 de enero, el norte y el sur desfilaban en procesiones y aparatosos desfiles de tambores, estandartes y antorchas; las enseñas de cada squadra se bendecían en las parroquias correspondientes; toda la sociedad participaba de una forma u otra en los preparativos de la gran confrontación, todos se contagiaban de una tensión que se iba acumulando hasta el día de la batalla: las madres del norte se insultaban con las del sur y prohibían a sus hijos ir a jugar al otro lado del puente; las plazas situadas a ambos extremos del puente se cerraban con empalizadas, formando recintos que habrían de servir como punto de partida para los propios combatientes y, en su caso, como punto de llegada o meta de los combatientes enemigos.

Los soldati que participaban en la batalla se entrenaban y equipaban como verdaderos soldados, llevaban armaduras y yelmos y manejaban como única arma ofensiva el llamado targone, una especie de escudo de madera estrecho y alargado que tenía de largo el brazo y dos tercios. Los combatientes se acometían y embestían con intención de dominar el centro del puente y, desde él, cargar hasta la meta situada en el extremo opuesto al propio; según testimonios de la época, la batalla duraba entre treinta y cuarenta y cinco minutos; durante la misma, muchos combatientes caían del puente y tenían que ser recogidos del agua por las embarcaciones desde las que muchos pisanos presenciaban la prueba. El

43 HEYWOOD, Palio and Ponte, pp. 93-137.

44 Por el norte participaban las squadre de San Antonio, con estandarte de llamas, San Martín (blanco, negro y rojo), San Marcos (blanco y amarillo), los Leoni (blanco y negro), los Dragoni (verde y blanco) y los Delfini (azul y amarillo); por el sur formaban: Santa María (azul y blanco), San Miguel (blanco y rojo), los Calci (verde, blanco y oro), la Calcesana (amarillo y negro), los Mattacini (blanco, azul y melocotón), y los Satiri (rojo y negro). 
juego terminaba con la victoria de uno de los dos bandos; los ganadores protagonizaban un gran desfile triunfal; los perdedores debían esperar un año para lanzar el desafío y disputar de nuevo con los vencedores. Y así discurría, entre ponte y ponte, la convivencia cívica sienesa, con la gran válvula de escape que por san Antonio, cada 17 de enero, se abría para expresar y aliviar las tensiones acumuladas durante todo el año. Sin duda, en el marco de la vida ciudadana, esta competición contaba con el apoyo institucional de las autoridades locales, pues ocupaba el lugar central como celebración cívico-deportiva en una de las principales fiestas, y como se aprecia, tanto en su origen como en su forma más evolucionada - que aquí se ha descrito- delata su primera motivación y sentido como ejercicio de preparación militar de la población en edad de empuñar las armas.

Otro festejo famoso, con un carácter distinto, es el Calcio de Florencia ${ }^{45}$, juego que - como es sabido - con el tiempo acabaría dando nombre en Italia a lo que modernamente llamamos fútbol. Cierto es que en este histórico juego dos bandos o equipos se disputaban la posesión de una pelota, y que podían desplazarla golpeándola con los pies; pero las similitudes con el fútbol actual prácticamente acaban ahí. Nuevamente, el origen del calcio florentino se halla en la evolución hacia formas consideradas menos cruentas de una verdadera batalla cívica armada. De combatir con armas se pasó a jugar por la posesión de una pelota, pero incluso en su forma evolucionada, el juego era duro y contenía todavía unos niveles elevados de violencia. Podemos describir con precisión sus reglas, al menos tal como se estabilizaron en la Baja Edad Media, a lo largo de los siglos XIV y XV. Existía un campo o terreno de juego, la Piazza de Santa Croce de Florencia, donde se delimitaba con una cerca un rectángulo de ciento setenta y dos brazas por ochenta y seis; sus lados menores se consideraban metas de cada equipo. Jugaban dos equipos, uno de verde, el otro de rojo, con veintisiete jugadores en cada uno, debiendo ser éstos ciudadanos honrados de Florencia en edad viril (esto es, entre dieciocho y cuarenta y cinco años, lo que significa en edad militar de combatir, y denota nuevamente el origen del juego como ejercicio de entrenamiento militar). En el centro del campo, una pelota se ponía en juego: el objetivo de ambos equipos era conducir esta pelota hasta la meta o confín del rival - hoy diríamos, hasta la «línea de gol» del adversario; cuando uno de los equipos conseguía que la pelota superara esta línea de gol del contrario, se anotaba una caccia o tanto; ganaba el equipo que anotaba más veces de esta forma, y con cada caccia (hoy diríamos, con cada «gol») los equipos intercambiaban su lugar en el campo. La forma de conducir la pelota de un lugar a otro era avanzar corriendo con ella en brazos (como todavía se hace hoy en el rugby y en el fútbol americano), o bien desplazarla a una distancia — pasándola o no a otro miembro del mismo equipo-, impulsándola mediante puñetazos y puntapiés, pero teniendo en cuenta que durante su recorrido, la pelota nunca debería superar la altura de un hombre: esto se

\footnotetext{
45 HEYWOOD, Palio and Ponte, pp. 161-176.
} 
consideraba una falta, y por cada dos faltas propias, el contrario se anotaba una caccia o tanto.

De inmediato se comprende que este juego tiene algunos puntos de contacto con lo que hoy llamamos fútbol, pero aún más con el moderno rugby, sin olvidar un ingrediente que en la época era fundamental: en último término, se trataba también de una batalla, y por eso, cuando decimos que la pelota se llevaba de un lado a otro golpeándola con los puños y con las piernas, no era nada raro, sino todo lo contrario, que algún puñetazo o alguna patada alcanzara a un rival. De hecho, era normal que los contendientes se desfogaran primero entre ellos, batiéndose a puñetazos y patadas, mientras la pelota yacía olvidada en algún rincón del campo, y sólo más tarde, cuando las fuerzas más frescas se habían consumido en una alegre contienda, alguien se acordaba por fin de la pelota y se iniciaba la tarea de anotar con ella las correspondientes caccias. De ahí que el calcio florentino fuera un juego bronco y rudo, que difícilmente se saldaba sin lesiones, y también este rasgo de su carácter (aspereza y marcialidad) se ha querido prolongar en las actuales reconstrucciones «historicistas» del juego, en las que a los participantes parece cuadrarles mejor la denominación de luchadores o practicantes de artes marciales que la de futbolistas o artistas del calcio en su acepción moderna.

\section{CONCLUSIÓN}

Un apunte importante en relación con estos juegos marciales anteriores al Renacimiento es su capacidad de supervivencia, indicio de su importancia en el contexto social de la vida ciudadana en aquellas comunidades del norte y centro de Italia. Con transformaciones y adaptaciones progresivas —unas más significativas que otras- estos y otros juegos llegaron hasta el Renacimiento y en algunos casos se prolongaron hasta el final del Antiguo Régimen e incluso hasta época contemporánea. Como hemos anotado a propósito del calcio florentino, distintas iniciativas en época actual tienden a reconstruir, recuperar y actualizar estos juegos, en razón de su atractivo turístico, pero también como identificación con el legado histórico de añosas tradiciones cívicas en la memoria y en la percepción social de estas comunidades italianas. Tanto el palio de Siena como el calcio de Florencia (Ilamado calcio storico fiorentino) se celebran en la actualidad, atraen atención y visitantes a sus respectivas ciudades y cuentan con numerosos seguidores y participantes. Sin embargo, su recreación, tal y como hoy se efectúa, tiene mucho más que ver, en indumentaria, enseres y equipamiento, e incluso en el reglamento y desarrollo, con la historia moderna de estos juegos, en la Italia del Renacimiento y del Barroco, antes que con sus orígenes medievales, peor documentados y de más difícil reconstrucción.

En cualquier caso, la cantidad, variedad y pormenores de todos los juegos competitivos derivados de modalidades de entrenamiento militar que se practica- 
ban en las ciudades del norte y centro de Italia desde antes del Renacimiento constituye un tema complejo, fascinante y rico en implicaciones de todo tipo, del que en estas páginas nos hemos contentado con dar una somera ilustración centrada en unos pocos ejemplos, y que entendemos suficiente para dar idea de su carácter y de su función social: educación y entrenamiento de la población, expresión y válvula de escape de tensiones y malos humores, afirmación patriótica del orgullo ciudadano son factores que hay que tomar en consideración al respecto, al lado de su vertiente lúdica y de simple recreo. 